\title{
THE USE OF MASTOID FASCIA FOR DORSAL NASAL AUGMENTATION
}

\author{
AHMED HASSAN EL-SABBAGH
}

\author{
Department of Plastic Surgery, Plastic Surgery Center, Faculty of Medicine, \\ Mansoura University, Egypt
}

\begin{abstract}
Background and aim. Dorsal augmentation of the nose is needed after trauma, rhinoplasty or for ethnic reasons. Alloplastic or autogenous materials may be used. In this paper, postauricular mastoid fascia was used for dorsal nasal augmentation.

Methods. This study included ten patients who underwent dorsal nasal

augmentation. Fascia over mastoid area was taken in all cases and was fixed with Steri-Strips and external nasal splints.

Results. All patients were female except one case. Five patients had the operation because of ethnic causes and five patients did the operation due to post traumatic deformity. Donor sites healed uneventfully. Digital photography was taken to assess the grafts and follow up was extended up to 9 months.

Conclusions. Mastoid fascia is a reliable method and its donor site is hidden. In addition, it can be a potential site for conchal graft if needed.
\end{abstract}

Keywords: dorsum of the nose, rhinoplasty, mastoid fascia

\section{Introduction}

Augmentation of the dorsum of the nose by a graft is a challenging problem for both the patient and the surgeon [1]. The cause may ethnic, traumatic or after rhinoplasty. Many types of grafts have been used such as fascia, cartilage and alloplastic materials [2-10].

No technique dominates. All have merits and demerits. Before choosing the method for augmentation, the operator should pay attention to previous trauma or operations, type of the skin and the availability of donor sites or alloplastic materials [11].

In this article, the autogenous tissue was used in the form of postauricular mastoid fascia for augmentation of the dorsum of the nose. This technique was adopted to simplify dorsal nasal augmentation and to minimize donor site morbidity.

\section{Patients and methods}

Ten cases underwent augmentation of the dorsum of the nose with open rhinoplasty from July 2012 to March 2016. Any patient who needs augmentation to the dorsum of his nose was included in the study. Informed consent was obtained from all patients involved in the study. Separate consent for photography was taken from all patients.

All patients were female except one patient (male) and their ages ranged between 21 and 39 years. A fascial graft was used in five patients due to post traumatic reasons and in five patients it was used to correct ethnic deformity. The male case was due to posttraumatic cause. This patient underwent rhinoplasty four times before with no improvement. 

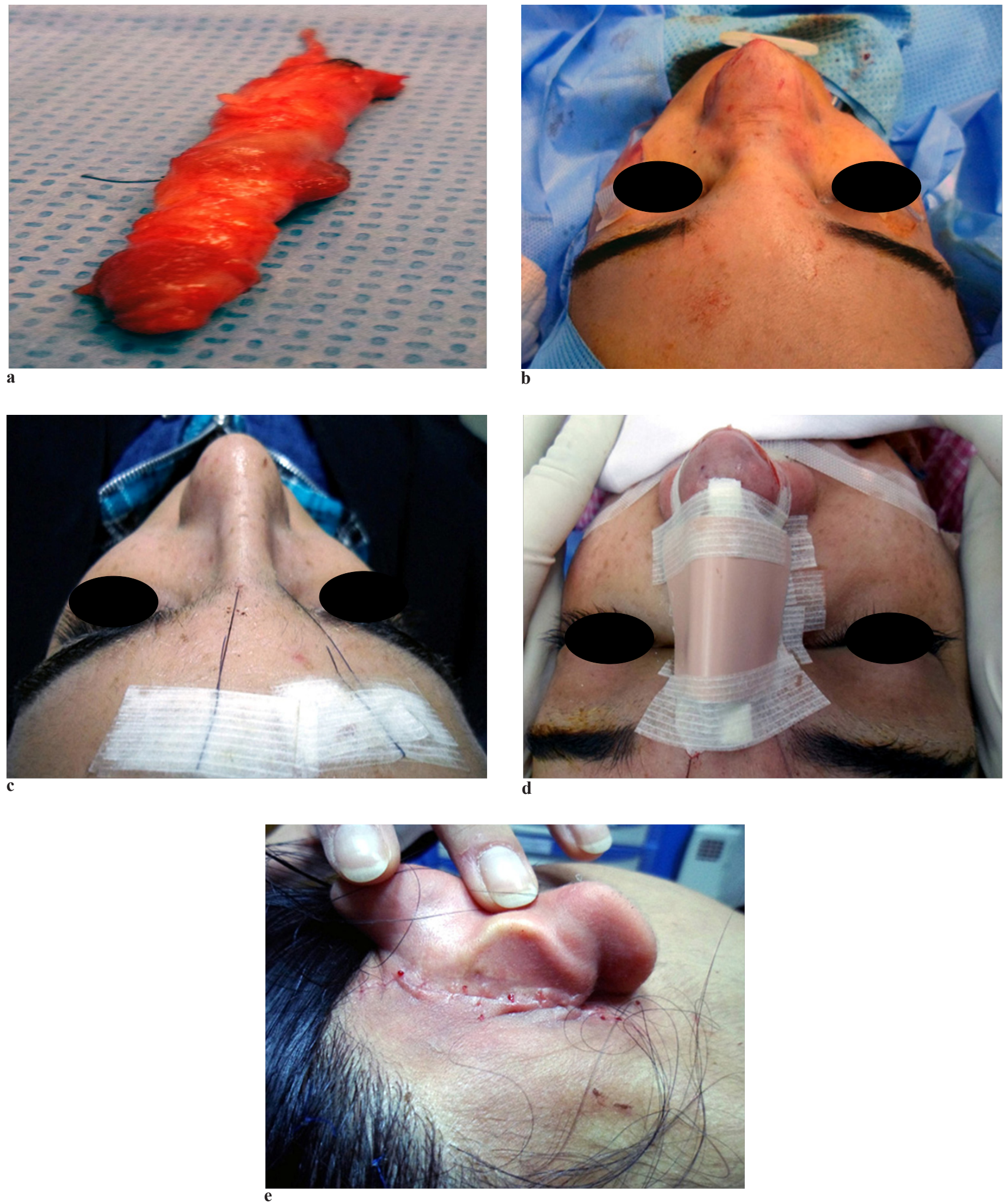

Figure 1. Surgical technique: a - Facial graft, $\mathbf{b}$ - Dorsum of the nose, $\mathbf{c}$ - Stabilization of the graft cranially by sutures fixed by SteriStrips, d - External splint, e - Donor site. 
Postauricular area was infiltrated subdermally with tumescent solution (saline with adrenaline at a concentration of $1 / 100.000$ ). This would facilitate the plane of dissection and could obtain a good hemostasis. Postauricular incision was made along postauricular crease with one $\mathrm{cm}$ perpendicular extension at both ends of the incision line. Fascial graft was harvested and then was rolled in by $5 / 0$ vicryl. The dimensions of the grafts varied from 1 X $3.5 \mathrm{~cm}$ to $1.5 \times 5 \mathrm{~cm}$.

Through open rhinoplasty, the fascial graft was inserted alone. All cases underwent tip definition by using the suturing technique. Non absorbable sutures $(5 / 0)$ and $(4 / 0)$ respectively were used. All operations were made without osteotomy. Two long vicryl $(2 / 0)$ sutures were passed through the dorsum of the nose to bring the cranial

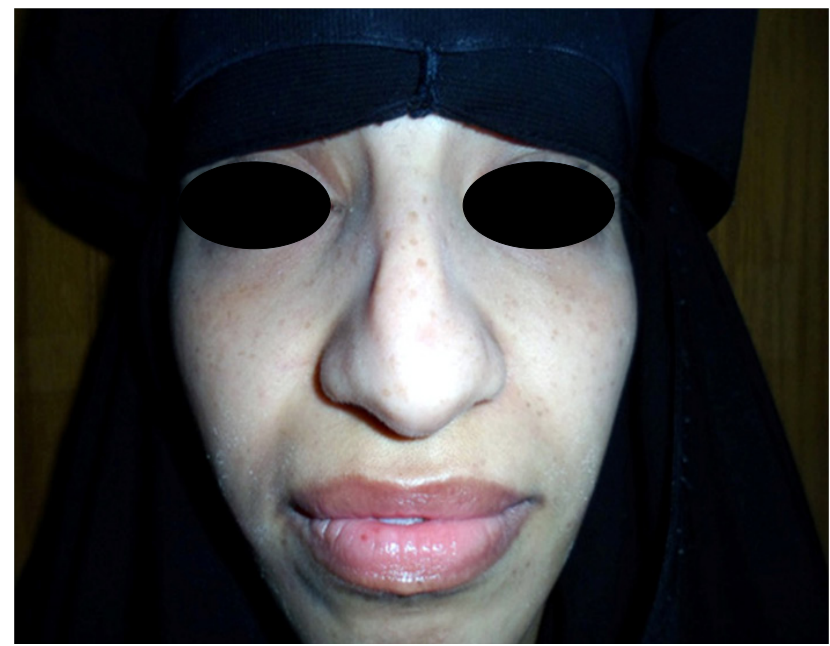

Figure 2. Post traumatic nose. a-Frontal view(preoperative).

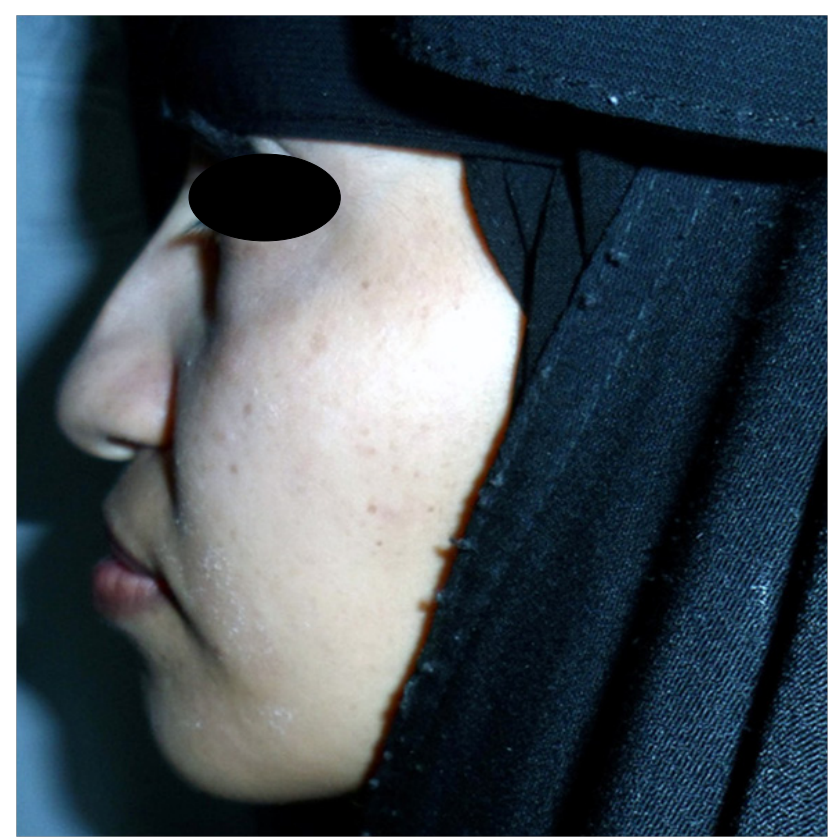

Figure 2. Post traumatic nose. c-Left lateral view (preoperative). end of the graft to the nasion. These sutures were stabilized by Steri-Strip on the forehead. This step was very important to ensure proper placement of the graft without movement. The external nasal splint was put over the dorsum.

\section{Postoperative care}

The sutures were removed after 10 days and the external splint was removed after 2 weeks. A clinical evaluation was made by photographic documentation.

All patients were evaluated with digital photography. Preoperative and postoperative photographs of some patients are presented. Follow up was extended up to 9 months postoperatively.

Results (Figures 2-4), (Table I)

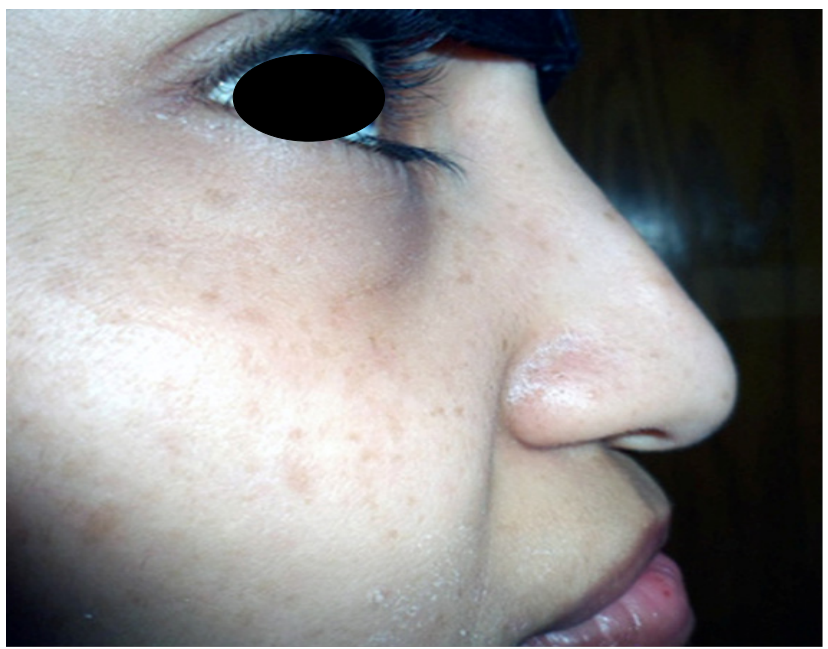

Figure 2. Post traumatic nose. b-Right lateral view (preoperative).

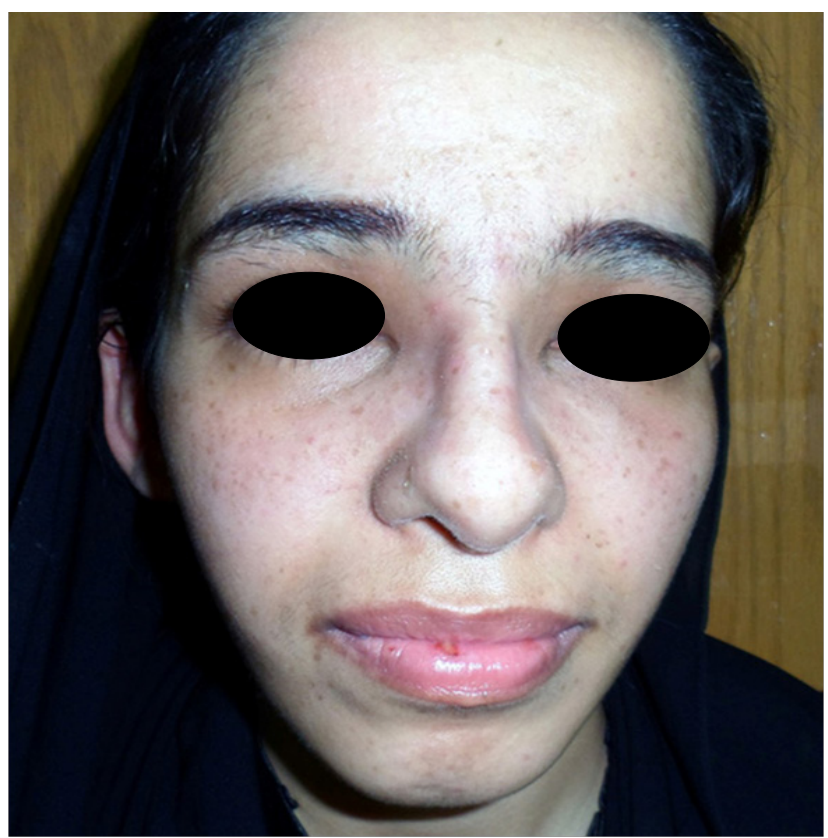

Figure 2. Post traumatic nose. d-Frontal view (3 months postoperative). 
Original Research

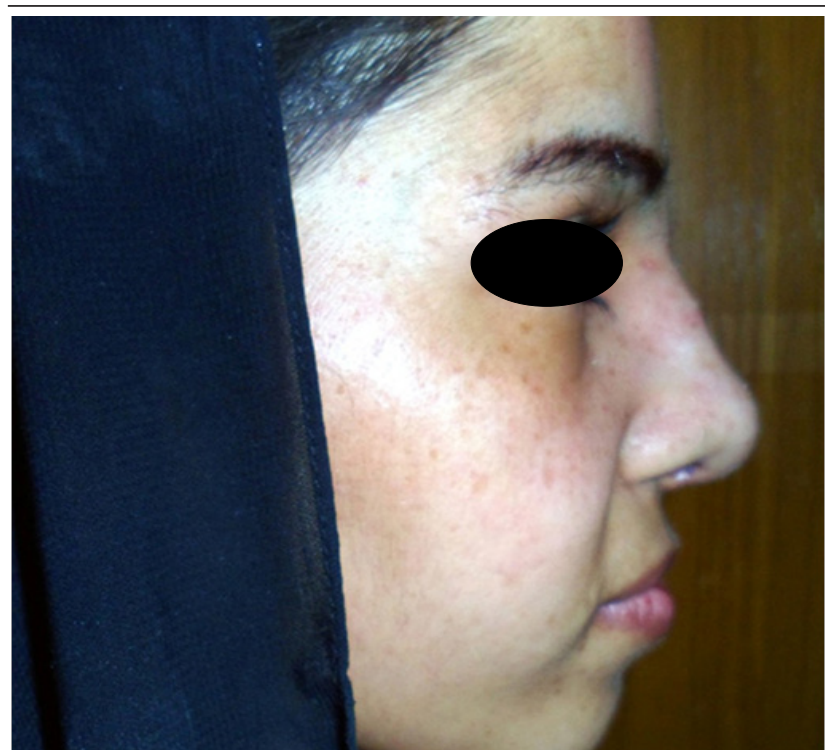

Figure 2. e-Right lateral view (3 months postoperative).
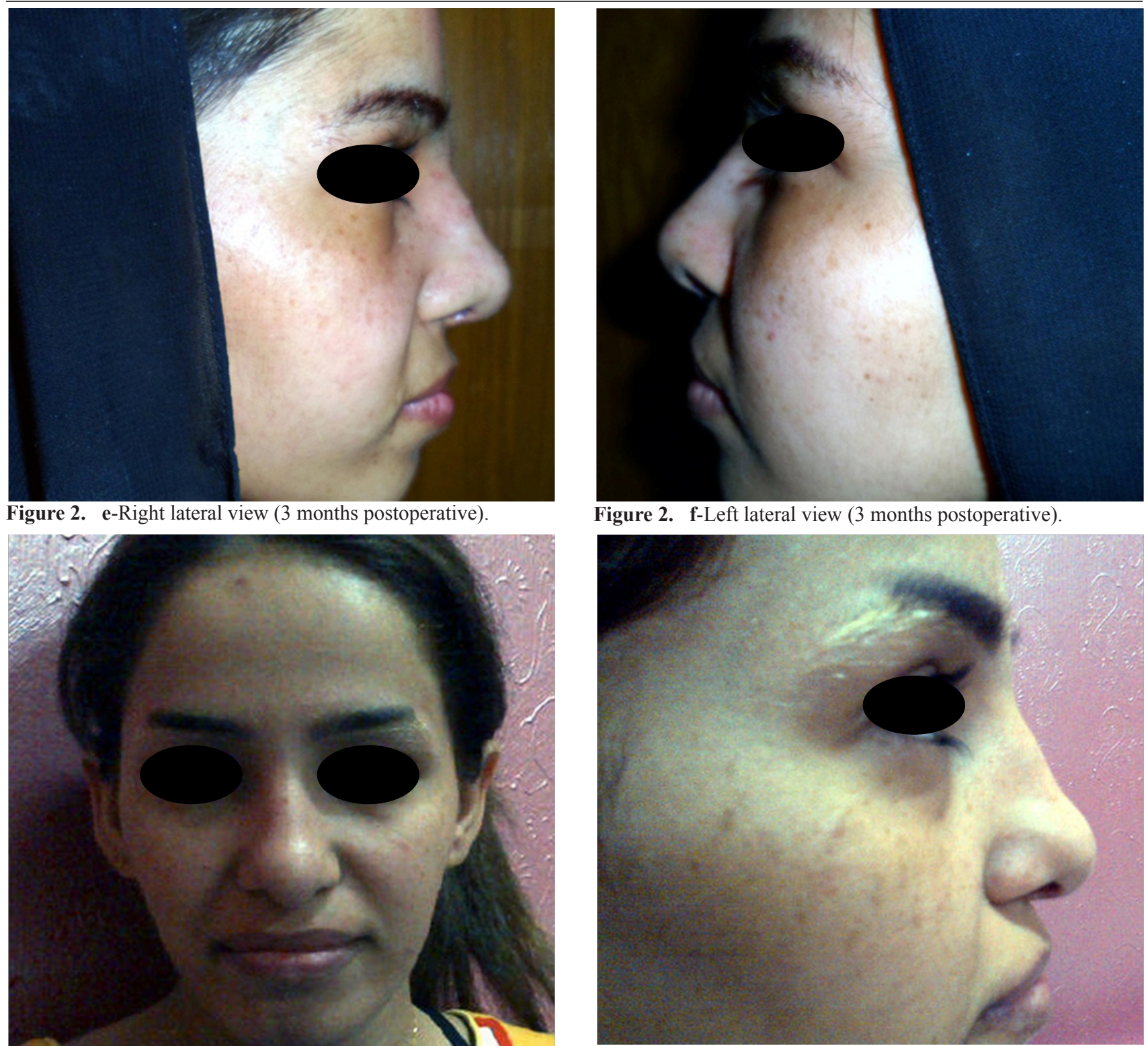

Figure 2. g-Frontal view (9 months postoperative).

Figure 2. f-Left lateral view (3 months postoperative).

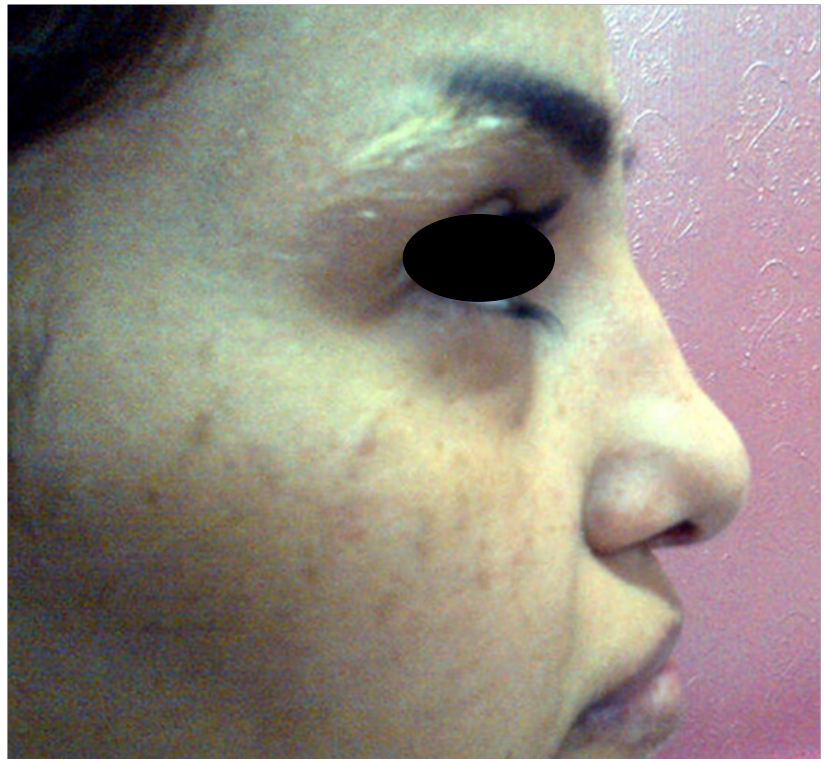

Figure 2. h-Right lateral view (9 months postoperative).

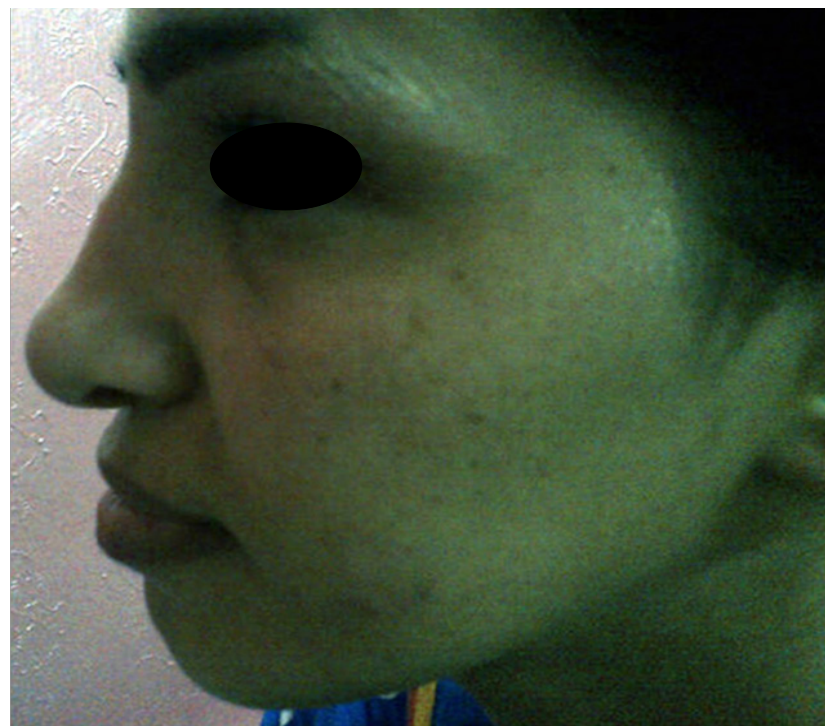

Figure 2. i-Left lateral view ( 9 months postoperative). 


\section{Surgery}
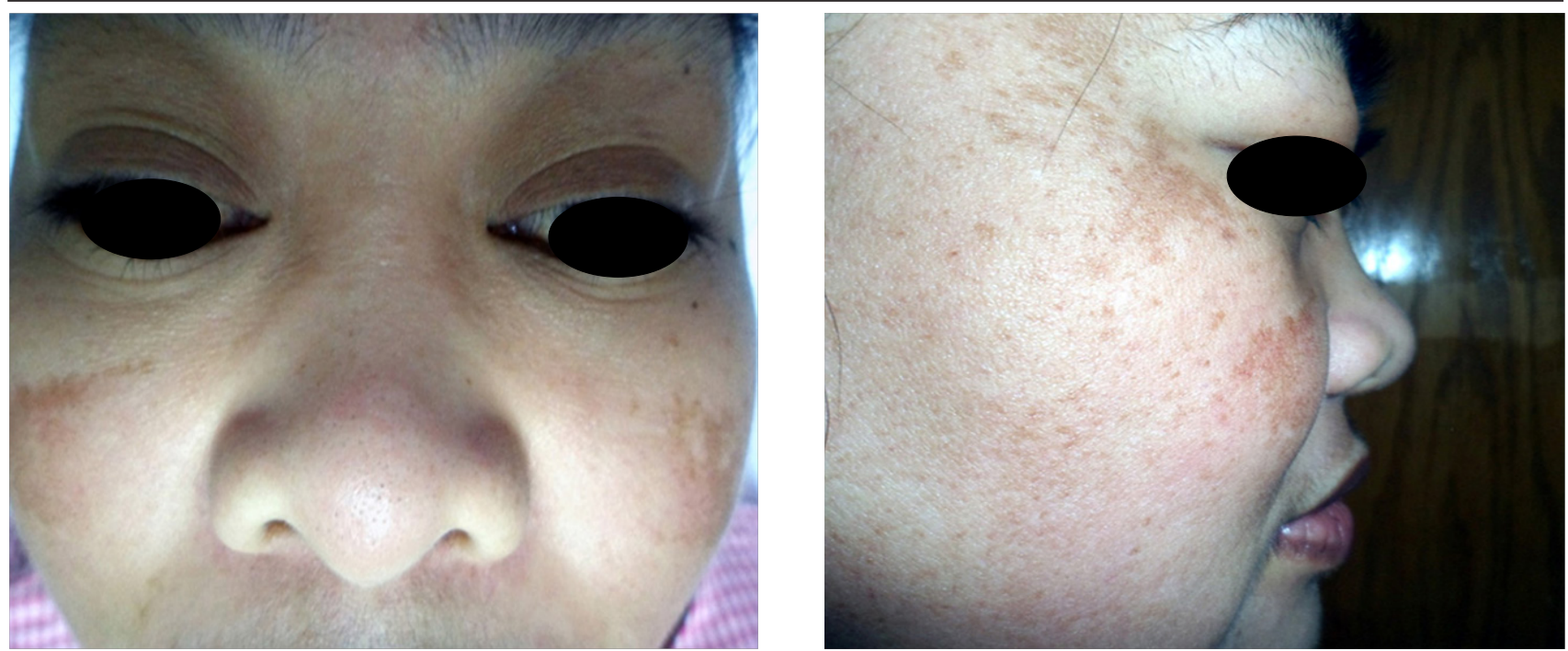

Figure 3. Asian nose. a-Frontal view (preoperative).

Figure 3. Asian nose. b-Right lateral view (preoperative).
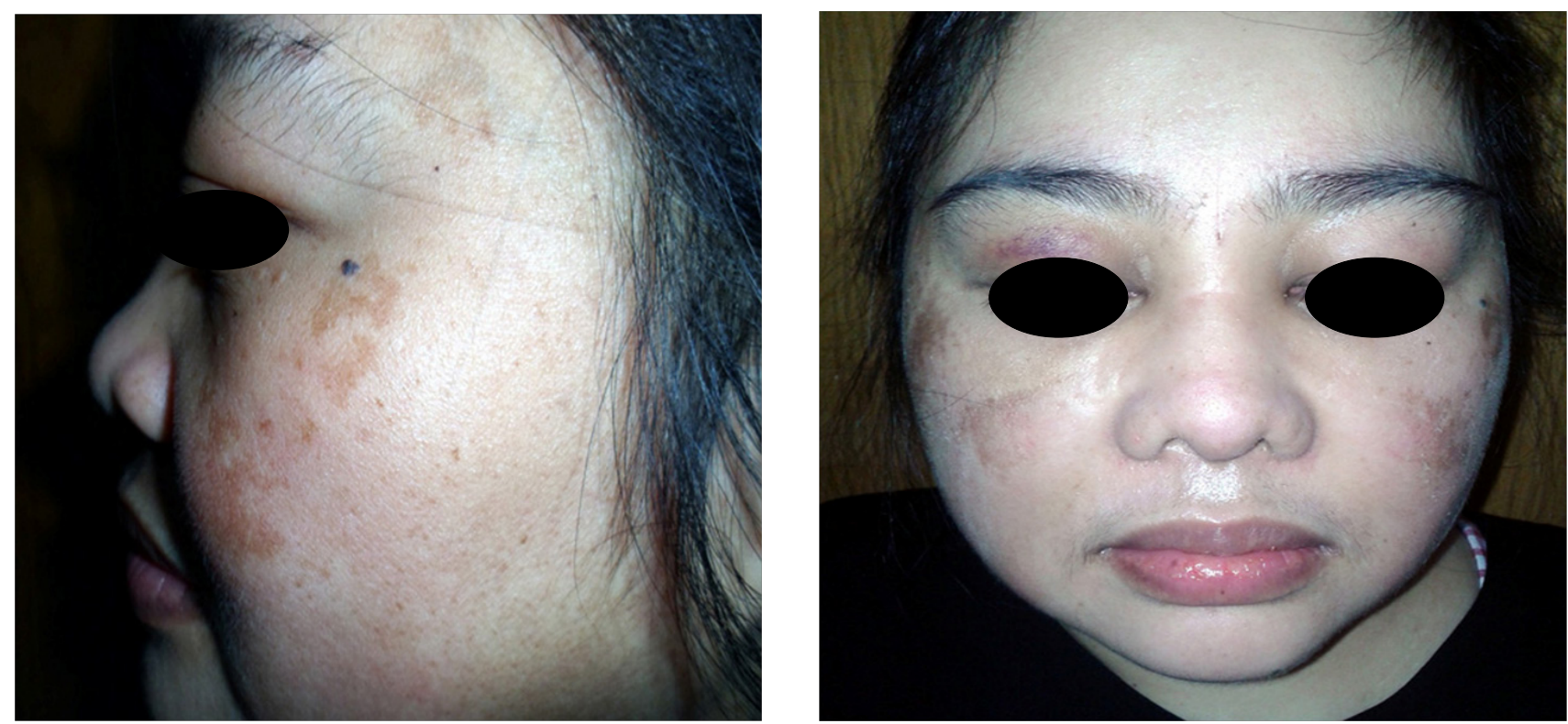

Figure 3. Asian nose. c-Left lateral view (preoperative).

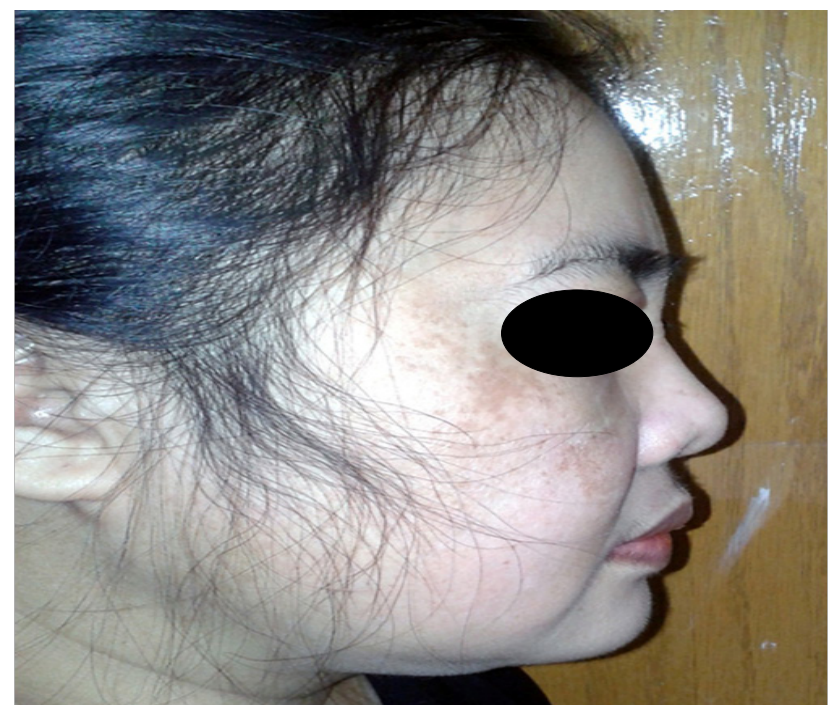

Figure 3. Asian nose. e-Right lateral view (3 months postoperative)

Figure 3. Asian nose. d-Frontal view (3 months postoperative).

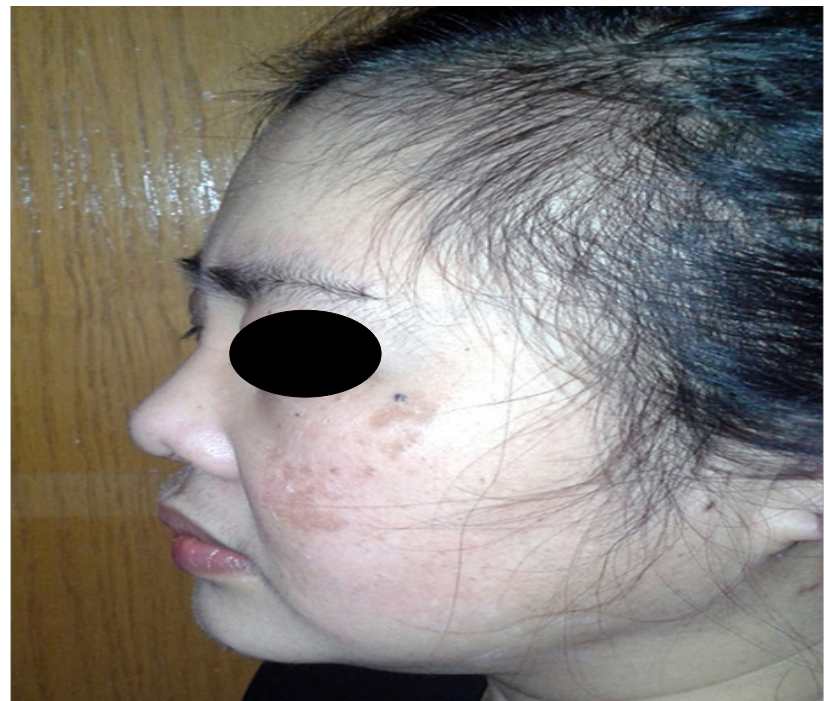

Figure 3. Asian nose. f-Left lateral view (3 months postoperative) 


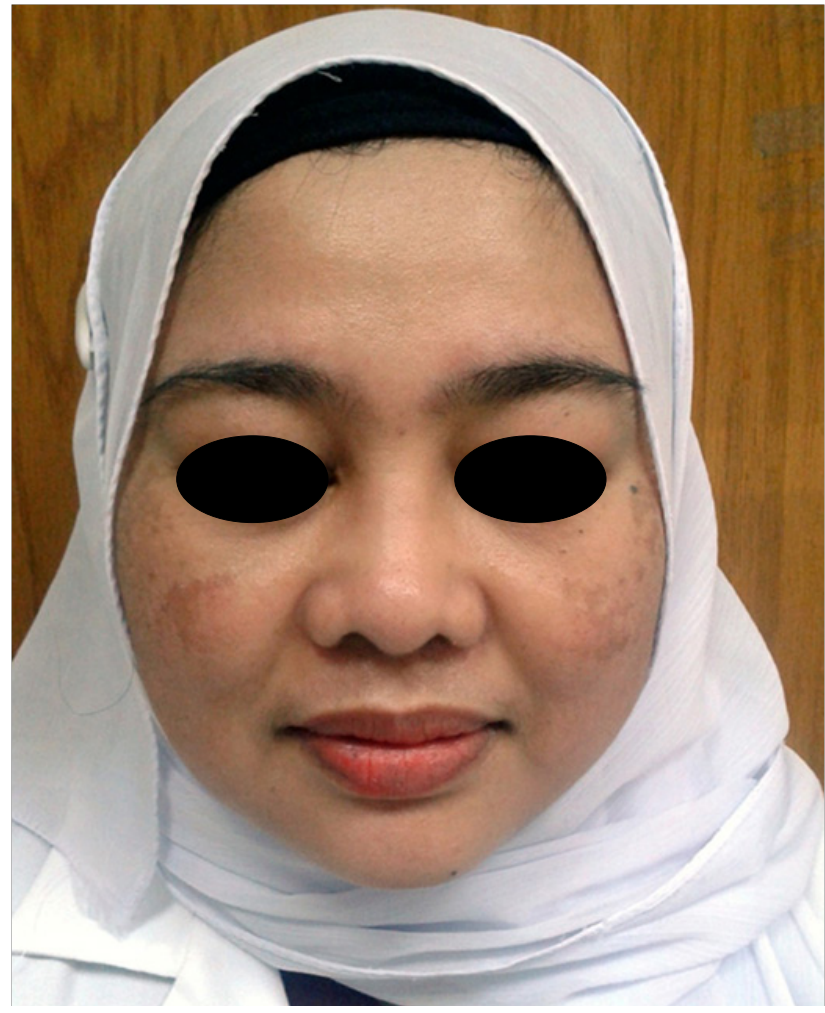

Figure 3. Asian nose. g-Frontal view (9 months postoperative).

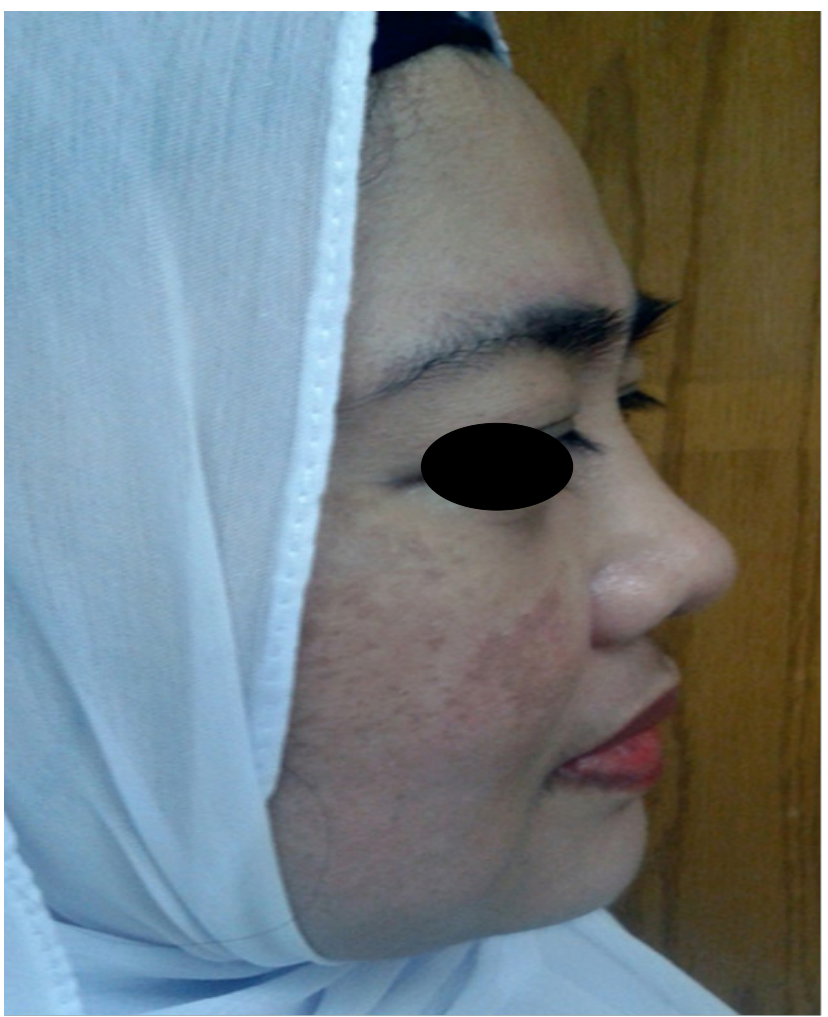

Figure 3. Asian nose. h-Right lateral view ( 9 months postoperative).

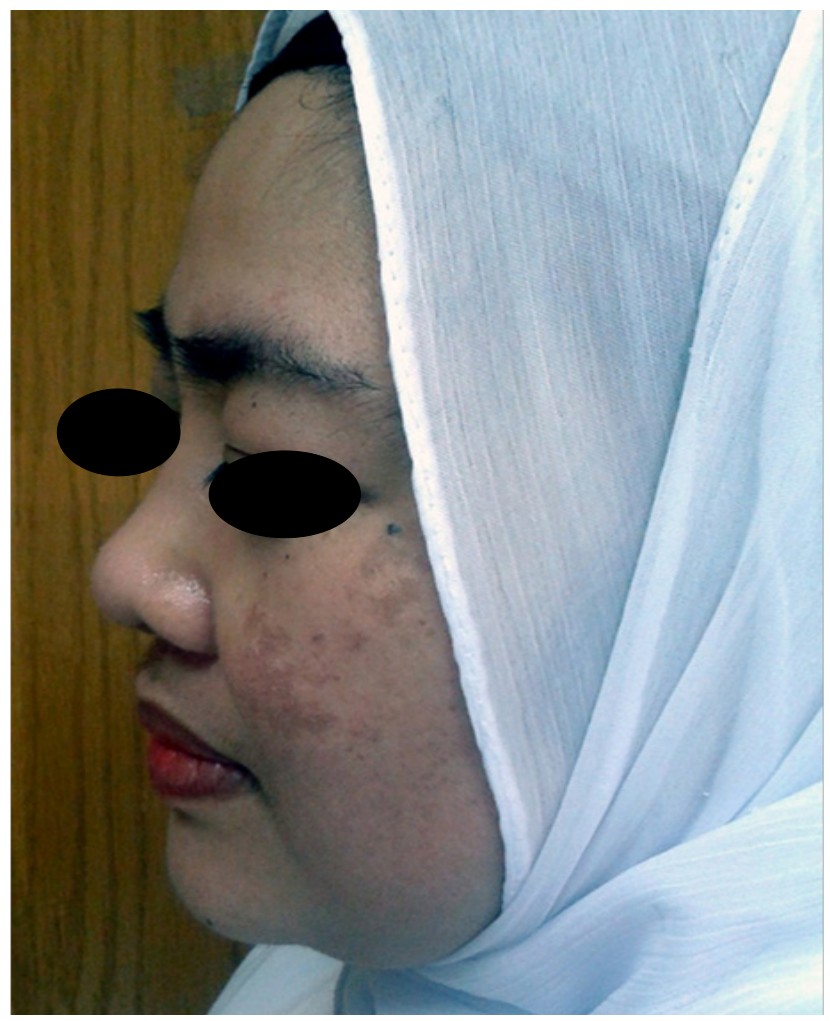

Figure 3. Asian nose. i-Left lateral view ( 9 months postoperative). 


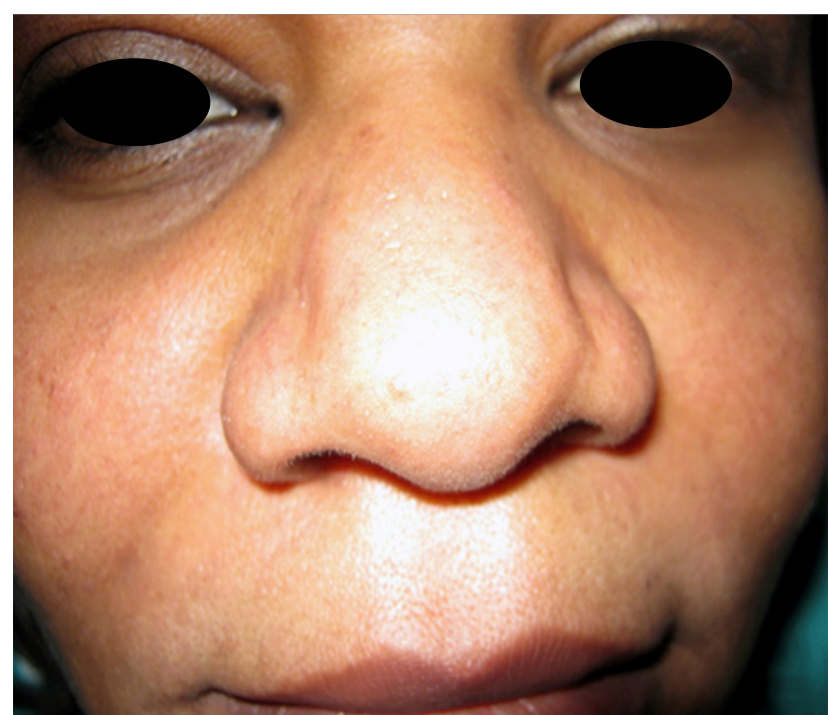

Figure 4. African nose. a-Frontal view (preoperative).

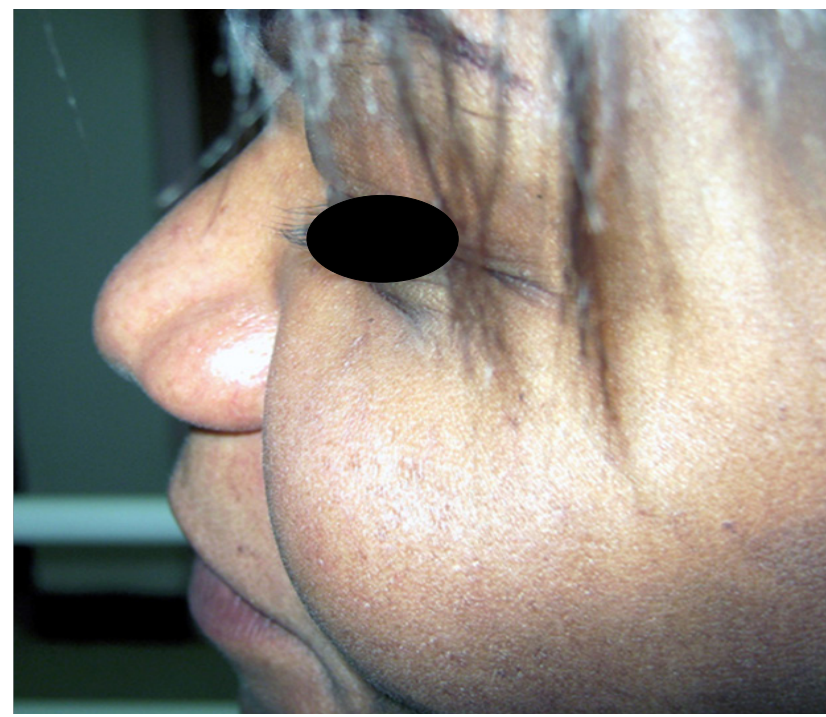

Figure 4. African nose. c-Left lateral view (preoperative).

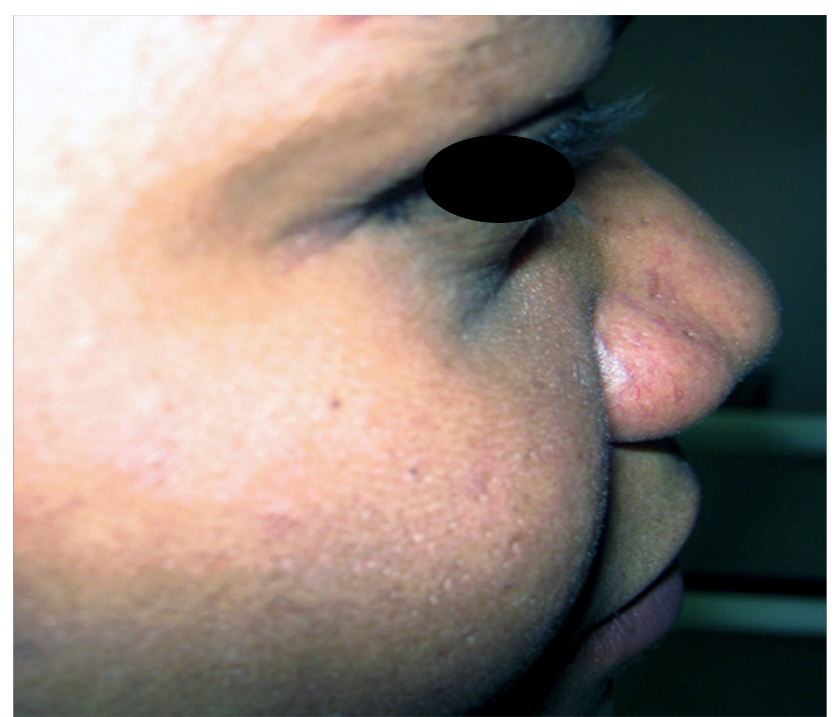

Figure 4. African nose. b-Right lateral view (preoperative).

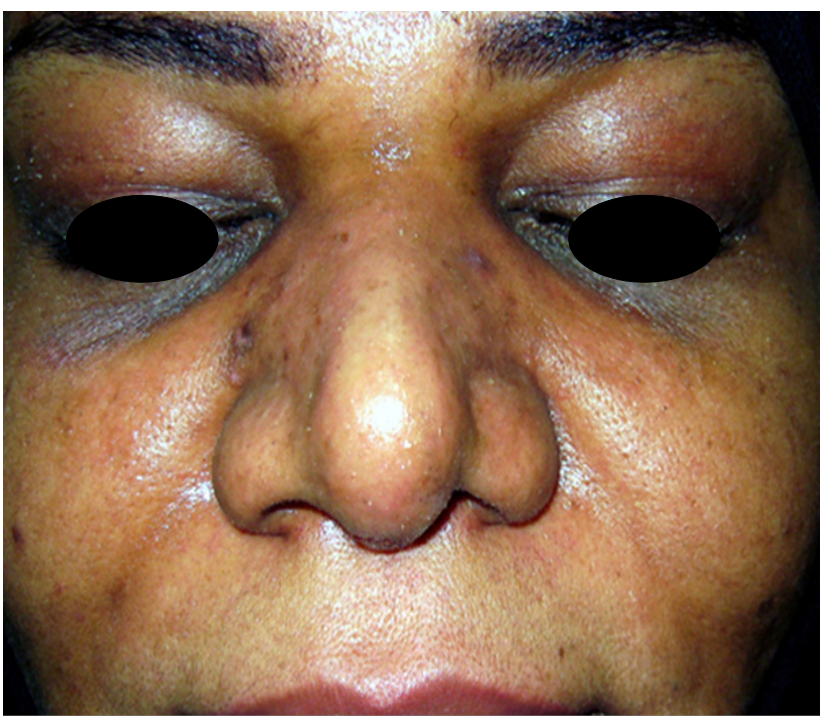

Figure 4. African nose. d-Frontal view (6 months postoperative).

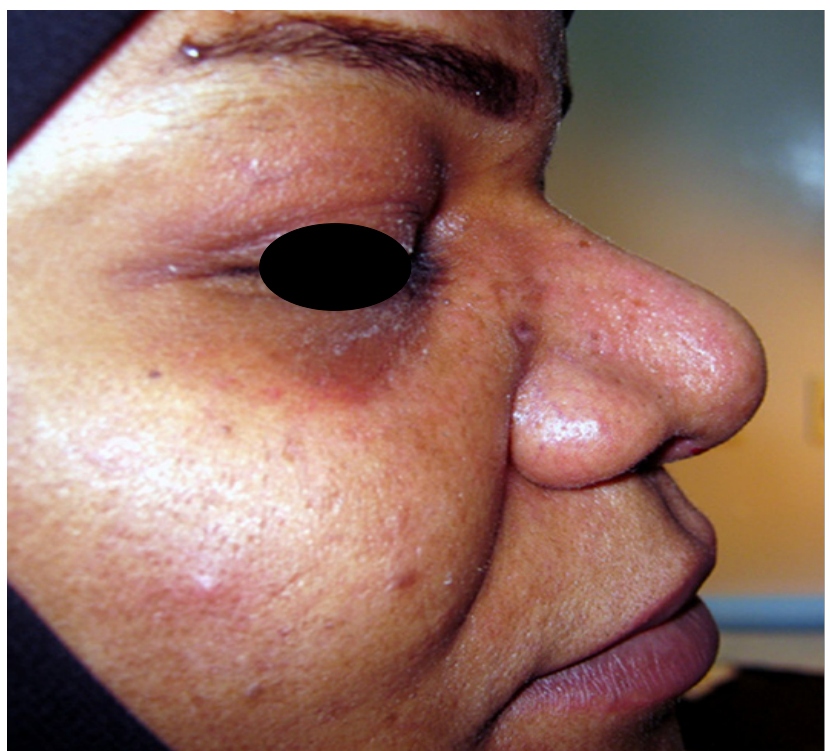

Figure 4.African nose. e-Right lateral view (6 months postoperative). 
Table I. Patients' Data.

\begin{tabular}{|l|l|l|l|l|}
\hline Number & Age & Gender & Etiology & Previous operation \\
\hline 1 & 33 & Female & Asian & - \\
\hline 2 & 36 & Female & Asian & - \\
\hline 3 & 23 & Female & Post traumatic & osteotomy \\
\hline 4 & 27 & Female & Post traumatic & - \\
\hline 5 & 34 & Female & African & - \\
\hline 6 & 29 & Female & African & - \\
\hline 7 & 30 & Female & Post traumatic & Conchal graft \\
\hline 8 & 21 & Female & Post traumatic & - \\
\hline 9 & 39 & Female & African & - \\
\hline 10 & 37 & Male & Post traumatic & Rhinoplasty (4 times ) \\
\hline
\end{tabular}
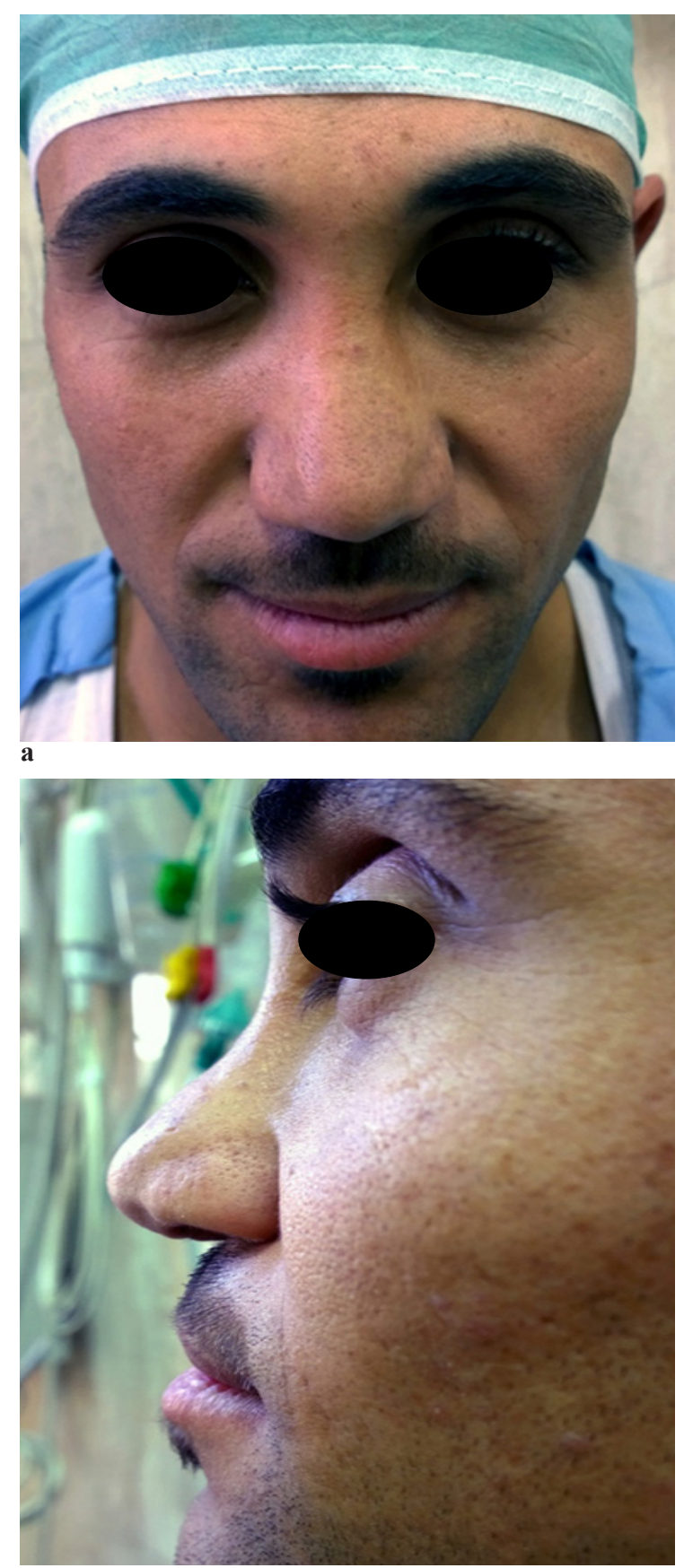

There were no apparent irregularities of the grafts. However, the male case showed fullness on the right ala (Figure 5). None of our patient asked for reoperation or searched for another opinion. Swelling in the early postoperative period (6 weeks) was accepted by all patients. There were no complaints from donor site scar as regard dysesthesia or hypoesthesia. One case showed hypertrophic scars at donor site. This was treated conservatively with topical corticosteroids. Hematoma of the donor site occurred in the first two operated cases and they were excluded from the study. Aspiration was done and the donor sites healed uneventfully.
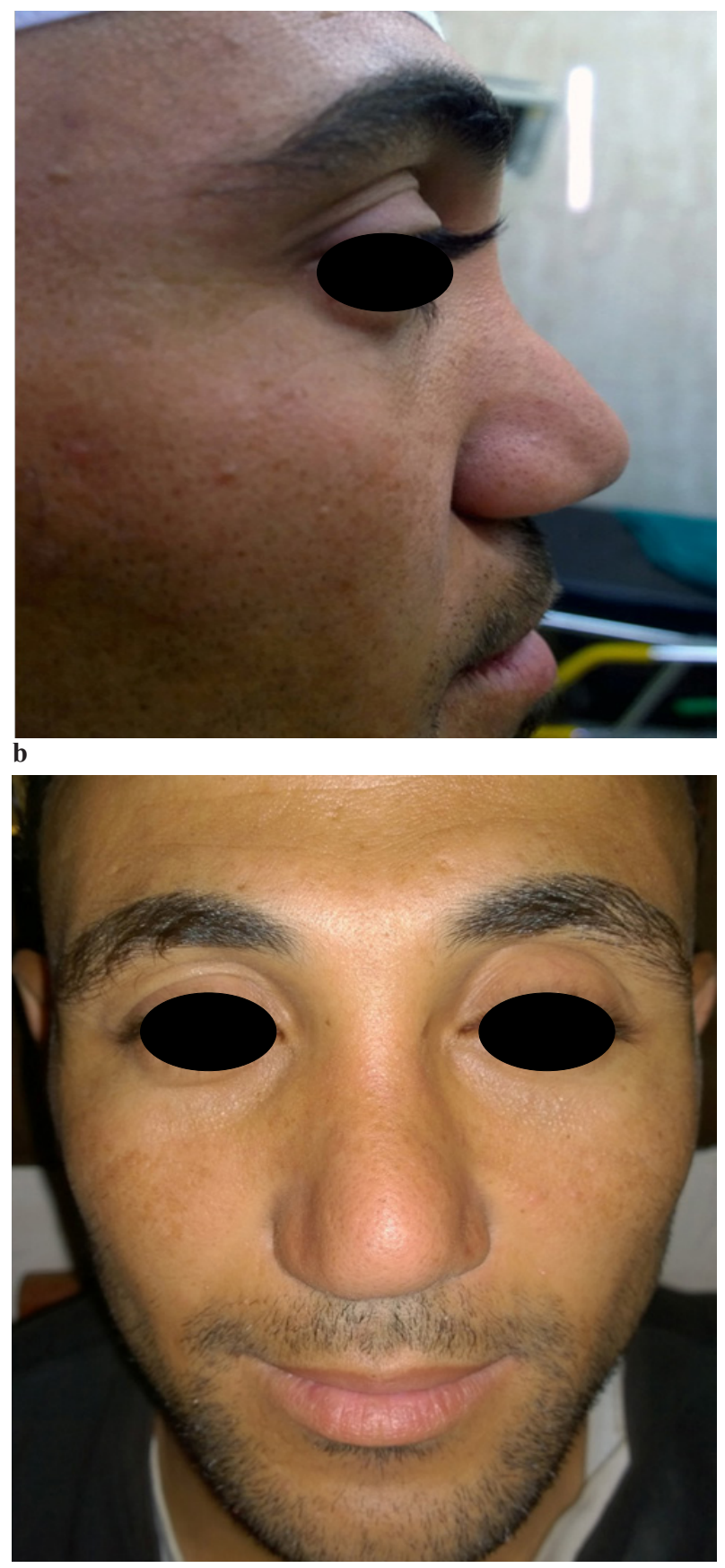


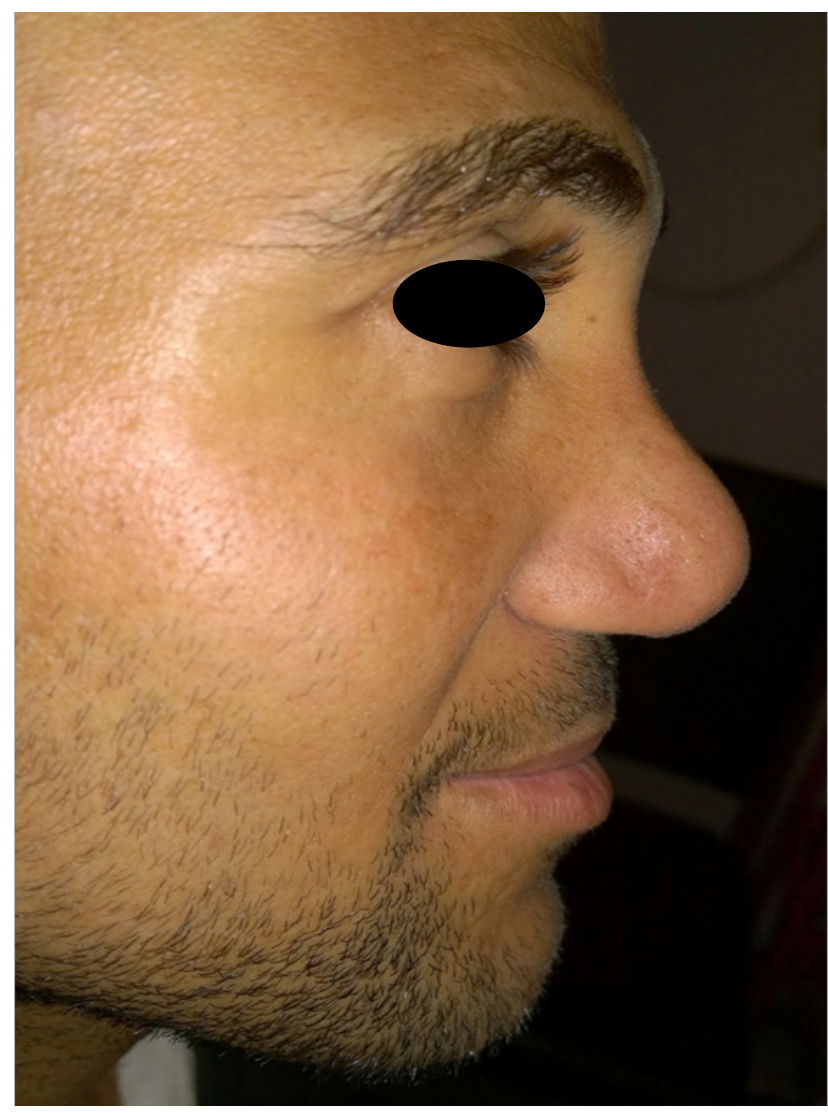

e

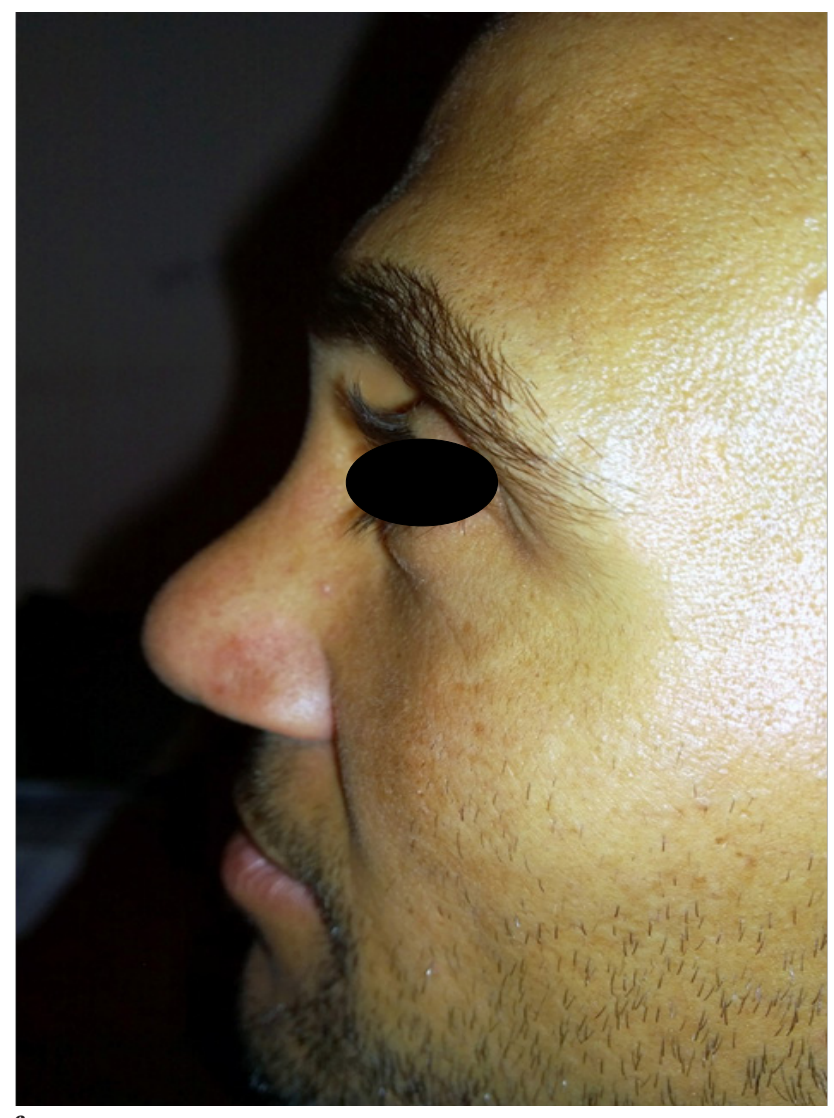

f

Figure 5. Post traumatic nose in male patient (operated 4 times before): a-Frontal view (preoperative), b-Right lateral view (preoperative), c-Left lateral view (preoperative), d-Frontal view (6months postoperative), Right lateral view (6 months postoperative), Left lateral view (6months postoperative).

\section{Discussion}

Autografts and allografts have been used extensively to improve the contour of the nose including its dorsum [1216]. As a type of autogenous material, many authors had used dermal grafts for augmentation rhinoplasty. Others have used deep temporal fascia for the same purpose [4]. Also, fascia lata was used effectively for correction of contour deformities of the nose. It has several advantages such as adequate amount could be obtained, easy technique and two teams can work simultaneously. However, its main drawbacks are seroma formation and unpleasant scar formation [17].

Septal grafts were used in different purposes for the nose. They can act as spreader grafts, on lay grafts and camouflage grafts. Disadvantages of septal cartilage are minimal but in some cases the septum is not sufficient in amount to augment the dorsum of the nose [18].

Grafts from conchal cartilage were used extensively for many years [19-24]. However, there is a particular concern about cartilage graft resorption, carving, migration and easy visibility of the graft in patients with thin skin and deficient subcutaneous tissue $[16,25]$.

As regard rib cartilage, it has many drawbacks such as learning curve is needed, pneumothorax may occur, and asymmetry of chest wall can present [26,27].

Unlike autogenous materials, alloplastic substances are available, easily molded with no donor site morbidity. However, liability for infection and extrusion of the graft still an issue [18]. Filler materials such as hyaluronic acid, Juvederm and calcium hydroxyapatite paste have been used. They have many drawbacks such as limited duration (4 to 9months), used for small defects and risk of infection is present [28-31].

There are a lot of tools to evaluate the viability of a graft as regard calculating the intake and revascularization, resorption and fibrosis percentages. These methods are anthropometric measurements before and after the surgery, non-invasive tests (ultrasonography, CT, MRI) and invasive tests (biopsy with histologic examination) [32-34].

Actually, the intake of autogenous fascial grafts and their usage for augmentation and correction for contour deformities stood the test of time [35]. This may explain why no other measurable tools were used to assess the viability and the intake of graft. In addition, one technique was used in all cases with no need for statistical assessment. Follow up of patients with photographs was extended up to 
6-9 months. This was quite sufficient to proof the validity of the graft.

Augmentation of the dorsum of the nose by postauricular mastoid fascia provides the surgeon with ample amount of fascia and enough length. The execution time was no more than 15 minutes and the donor sites were hidden. Also, there is a possibility to augment the graft with conchal cartilage from the same incision.

In contrast to other authors, mastoid fascia was used to augment the dorsum of the nose for both ethnic and posttraumatic causes. In addition, mastoid fascia was used alone without augmentation with of septal or conchal cartilages [36,37].

In all cases, augmentation of the nose did not require harvesting from both sides of the ears. No additional cartilages were added even in posttraumatic cases. Also, there was no need for osteotomy to augment the dorsum of the nose. Postoperative swelling was accepted in the first 6 weeks. Usage of nasal splint for 14 days minimizes the swelling and keeps the graft in place. Massage of the dorsum of the nose was prevented to avoid displacement and inadequate intake of the graft.

In summary, the novelty in this article was the use of postauricular mastoid fascia alone for dorsal nasal augmentation in ethnic and posttraumatic noses. No doubt, the donor site was clearly superior to other methods. Moreover, it is a potential site for conchal graft if needed.

\section{Conclusion}

Dorsal nasal augmentation can be done with a variety of available grafts, implants or fillers. The ideal reconstructive method should have good intake, minimal donor site morbidity, less inflammatory response and long lasting results. The postauricular mastoid fascia fulfills all these requirements.

\section{Ethical standards}

This study was performed in accordance with the ethical standards set forth in the 1964 Declaration of Helsinki and its later amendments. Informed consent was obtained from all parents responsible for participants included in the study.

\footnotetext{
References

1. Romo T 3rd, Sonne J, Choe KS, Sclafani AP. Revision rhinoplasty. Facial Plast Surg. 2003;19(4):299-307.

2. Erol OO. The Turkish delight: a pliable graft for rhinoplasty. Plast Reconstr Surg. 2000;105(6):2229-2241.

3. Baker TM, Courtiss EH. Temporalis fascia grafts in open secondary rhinoplasty. Plast Reconstr Surg. 1994;93(4):802-810.

4. Erdogan B, Tuncel A, Adanali G, Deren O, Ayhan M. Augmentation rhinoplasty with dermal graft and review of the literature. Plast Reconstr Surg. 2003;111(6):2060-2068.

5. Jackson IT, Yavuzer R, Silverstein P. AlloDerm for Dorsal Nasal Irregularities. Plast Reconstr Surg. 2001;107(2):559-560.

6. Gryskiewicz JM, Rohrich RJ, Reagan BJ. The use of alloderm
}

for the correction of nasal contour deformities. Plast Reconstr Surg. 2001;107(2):561-570.

7. Gajiwala K, Lobo Gajiwala A. Use of banked tissue in plastic surgery. Cell Tissue Bank. 2003;4(2-4):141-146.

8. Crawford JS. Repair of ptosis using frontalis muscle and fascia lata: a 20-year review. Ophthalmic Surg. 1977;8(4):31-40.

9. Jang YJ, Wang JH, Sinha V, Song HM, Lee BJ. Tutoplastprocessed fascia lata for dorsal augmentation in rhinoplasty. Otolaryngol Head Neck Surg. 2007;137(1):88-92.

10. Ham J, Miller PJ. Expanded polytetrafluoroethylene implants in rhinoplasty: literature review, operative techniques, and outcome. Facial Plast Surg. 2003;19(4):331-339.

11. Miller TA. Temporalis fascial grafts. Plast Reconstr Surg. 1980;65:236-237.

12. Juri J, Juri C, Elías JC. Ear cartilage grafts to the nose. Plast Reconstr Surg. 1979;63(3):377-382.

13. Conley J. Intranasal composite grafts for dorsal support. Arch Otolaryngol. 1985;111(4):241-243.

14. Gunter JP, Rohrich RJ. External approach for secondary rhinoplasty. Plast Reconstr Surg. 1987;80(2):161-174.

15. Gunter JP, Rohrich RJ. Augmentation rhinoplasty: dorsal onlay grafting using shaped autogenous septal cartilage. Plast Reconstr Surg. 1990;86(1):39-45.

16. Constantian MB. Distant effects of dorsal and tip grafting in rhinoplasty. Plast Reconstr Surg. 1992;90(3):405-418.

17. Karaaltin MV, Orhan KS, Demirel T. Fascia lata graft for nasal dorsal contouring in rhinoplasty. J Plast Reconstr Aesthet Surg. 2009;62(10):1255-1260.

18. Daniel RK, Sajadian A. Secondary rhinoplasty: management of the overresected dorsum. Facial Plast Surg. 2012;28(4):417-426.

19. Boccieri A, Marano A. The conchal cartilage graft in nasal reconstruction. J Plast Reconstr Aesthet Surg. 2007;60(2):188194.

20. Boccieri A. Subtotal reconstruction of the nasal septum using a conchal reshaped graft. Ann Plast Surg. 2004;53(2):118-125.

21. Dyer WK 2nd, Yune ME. Structural grafting in rhinoplasty. Facial Plast Surg. 1997;13(4):269-277.

22. Arden RL, Crumley RL. Cartilage grafts in open rhinoplasty. Facial Plast Surg. 1993;9(4):285-294.

23. Neu BR. Combined conchal cartilage-ethmoid bone grafts in nasal surgery. Plast Reconstr Surg. 2000;106(1):171-175.

24. Farrior EH. Revision rhinoplasty for monographs in facial plastic surgery contemporary rhinoplasty. Facial Plast Surg. 1997;13(4):299-308.

25. Tuncali D, Aslan G, Terzioğlu A. Fate of diced cartilage grafts wrapped with oxidized regenerated cellulose. Plast Reconstr Surg. 2003;111(5):1767-1768.

26. Sertel S, Venara-Vulpe II, Pasche P. Correction of severe columella and tip retraction in silicone implanted Asian short noses. J Otolaryngol Head Neck Surg. 2016 Mar 10;45:19. doi: 10.1186/s40463-016-0131-9.

27. Nuara MJ, Loch RB, Saxon SA. Reconstructive Rhinoplasty Using Multiplanar Carved Costal Cartilage. JAMA Facial Plast Surg. 2016;18(3):207-211.

28. Lowe NJ, Maxwell CA, Lowe P, Duick MG, Shah K. Hyaluronic acid skin fillers: adverse reactions and skin testing. J Am Acad Dermatol. 2001;45(6):930-933.

29. Duranti F, Salti G, Bovani B, Calandra M, Rosati ML. Injectable hyaluronic acid gel for soft tissue augmentation. A clinical and histological study. Dermatol Surg. 1998;24(12):13171325 . 
30. Maas CS, Papel ID, Greene D, Stoker DA. Complications of injectable synthetic polymers in facial augmentation. Dermatol Surg. 1997;23(10):871-877.

31. Rudolph CM, Soyer HP, Schuller-Petrovic S, Kerl H. Foreign body granulomas due to injectable aesthetic microimplants. Am J Surg Pathol. 1999;23(1):113-117.

32. Burget GC, Walton RL. Optimal use of microvascular free flaps, cartilage grafts, and a paramedian forehead flap for aesthetic reconstruction of the nose and adjacent facial units. Plast Reconstr Surg. 2007;120(5):1171-1207.

33. Rohrich RJ, Ghavami A. Rhinoplasty for Middle Eastern noses. Plast Reconstr Surg. 2009;123(4):1343-1354.

34. Hashim HA, AlBarakati SF. Cephalometric soft tissue profile analysis between two different ethnic groups: a comparative study. J Contemp Dent Pract. 2003;4(2):60-73.

35. Thompson N. The subcutaneous dermis graft. A clinical and histologic study in man. Plast Reconstr Surg Transplant Bull. 1960;26:1-22.

36. Hong ST, Kim DW, Yoon ES, Kim HY, Dhong ES. Superficial mastoid fascia as an accessible donor for various augmentations in Asian rhinoplasty. J Plast Reconstr Aesthet Surg. 2012;65(8):10351040 .

37. Dogan T, Aydin HU. Mastoid fascia tissue as a graft for restoration of nasal contour deformities. J Craniofac Surg. 2012 Jul;23(4):e314-e316. doi: 10.1097/SCS.0b013e318254333d. 